\title{
Application of Indigenous Folk Wisdom Concerning the Management of Commercial Reed-Mat Production in Maha Sarakham Province, Thailand
}

\author{
Songkoon Chantachon ${ }^{1}$ \\ ${ }^{1}$ The Faculty of Cultural Science, Mahasarakham University, Khamriang Sub-District, Kantarawichai District, \\ Maha Sarakham, Thailand \\ Correspondence: Nuengruethai Coulson, 391/12 Moo 5, Nongchang Sub-District, Nongchang District, Uthai \\ Thani, Thailand. E-mail: david.coulson.6@gmail.com
}

Received: February 4, 2013 Accepted: March 5, 2013 Online Published: April 27, 2013

doi:10.5539/ass.v9n5p51 URL: http://dx.doi.org/10.5539/ass.v9n5p51

\begin{abstract}
A dying skill in a thriving economy, reed-mat production is fast losing its identity as a traditional Thai handicraft. This qualitative research analyzes how local wisdom is used in the management of commercial reed-mat production in Maha Sarakham Province, Thailand. Once-distinctive Thai reed-mats are now being mass-produced to cope with global demand, killing the economic viability of hand produced merchandise. This study identifies problems with materials, equipment, production process, product development and finance as causing a loss of unique character in reed-mat goods. This article provides solutions for application to career development in local communities and the management of ancestral community knowledge.
\end{abstract}

Keywords: folk wisdom, reed-mat, production, Maha Sarakham province, community development

\section{Introduction}

Beneath the context of rapidly changing trends of globalization, it is necessary to determine an appropriate national development strategy. This is achieved by strengthening the structures of various systems within the country in order to give them the capability to compete on a global level and create knowledge to make them immune to change. It is also necessary to reinforce social equality and community strength, at the same time as restoration and conservation of natural resources and environmental quality. This will provide a perfect foundation for stable development and maintenance of Thai community and social lifestyle, including the strengthening of good governance at every level of national administration. National development on this model will be stable, lasting and able to remain in the global community with dignity and prestige. The Thai government implemented such a plan in 2008, an important development strategy of the $10^{\text {th }}$ National Economic and Social Development Plan. This strategy concerned the building of strength in the community and society so that it would be a firm foundation of the country. It gave importance to building economic security in the community, while ensuring that potential integration, process and production were balanced with the strength of the community.

The details of the plan placed emphasis on sufficient production for community consumption, which would unify the community in social cooperatives. Work groups were also expected to support knowledge and local culture that could be used in creation of product value and service. Other aspects of the plan included building cooperation in private investment, job and income creation that had fair and mutual benefit for everyone in the community, promotion of investment between networks of community organizations and local administrative organizations, creation of developed community corporations, strengthening of community potential to exist in harmony with natural resources and promotion of community rights. These, given adequate levels of community participation in conservation, would restore development to a more beneficial and efficient level, while creating a mechanism to protect natural resources and the surrounding environment.

A development strategy on the basis of biological variety and creation of security in natural resources and surrounding environment will necessarily place importance upon development of variety and indigenous knowledge. This is achieved in Thailand by using the sufficiency economy policy of King Bhumibol Adulyadej as the primary method. Protection of knowledge and biological variety from external threats, especially from 
international competition, will create systems guarding community rights and produce fair, mutually beneficial results. This attitude strengthens the use of biological variety in the creation of stability in the local economy, develops the limits of potential and creates innovations of national identity from biological resources.

The North-Eastern region of Thailand, colloquially known as the Isan region, is a prominent area that has a variety of arts, cultures, customs and lifestyles, which are not restricted to the geographical boundaries of the region. Therefore, Isan is the area with the largest population in the country and has a clearly visible variety of ethnic backgrounds. Aside from this, it remains the region with the most wide-ranging problems, such as drought, poverty and economic migration. Currently, some problems have been solved to make the Isan region as prosperous as other areas. Even though a large number of people consider Isan people to be uneducated, poor, sickly and pitiful, the reality is that people or societies in the region do not live their lives without gathering experience or knowledge. Isan people use their intelligence to gather knowledge, which can be seen in local proverbs, or Payagom. A number of these promote social values concerning community attitude, the value of occupational knowledge and the respect of knowledge and its use.

The majority of the Isan population is employed in agriculture and arable farming. The most important crops are rice, cassava, jute and corn. There are poor harvests due to the porous, sand-based Isan soil and most agriculture relies on rainfall, which makes it unreliable. Some years there is high rainfall, yet in other years there is minimal rain and river levels are low. The lack of water in the area means there is no further planting after harvest. Consequently there are few crops, causing widespread poverty in the local population and the need for secondary employment aside from agriculture. This employment includes manual labour (it was found that a large number of people migrate to find work during the dry season) and independent jobs related to folk wisdom, such as fabric weaving, mat weaving and other handicrafts within the personal skill-set of the individual.

Folk wisdom is therefore concerned with production and local way of life, including festivals, community ceremonies and traditions. The wisdom helps to make performers feel comfortable, warm and not alone, giving mental value to their activities and promoting a feeling of moral strength. Generally, folk wisdom is a plain and simple model of life that is not complicated and benefits all social groups. The prominent characteristic of folk wisdom is creation of an elite group in both nuclear and extended families to oversee the use of production results in everyday life, which primarily consist of souvenir manufacture for visitors and sale. The results enable individuals to generate income for their families and allow members of the community to invest or spend for sustained living, that which is related to satisfaction and both mental and physical necessity.

Reed-mat weaving is a supplementary occupation of agricultural society and the workers are fully devoted to their profession. It is a supplementary occupation that specifically indicates the existence of an initial thought-process, integration, community-beneficial inheritance and pride in work completion. This is a result of the professional devotion of individuals and groups who earn a living from reed-mat weaving. In turn the dedicated inventors or interested parties try to educate themselves in the concepts of shape and working procedure by learning from knowledgeable members of the community or similar communities. The education will take place until the student skill and expertise in some or all procedures of reed-mat weaving. From the first procedure until the last, reed-mat weaving is a folk handicraft that residents practice according to local folk wisdom. The mats are created as groundcovers for sleeping and sitting on and used in the family, distributed to relatives as gifts, given as souvenirs to visitors, used in the practice of making merit at local festivals and sold or bartered.

Practice of the reed-mat weaving occupation is classified into two groups, which are primary occupation and secondary occupation. Reed-mat weaving is a local handicraft that has been inherited from the ancestral past. The mats have different names according to the materials used in their construction. Seua Gog are reed-mats made from flatsedge. If the plants used are of the round variety, the reed-mats are named Seua Jantaboon, while mats made from edged-flatsedge are named Seua Peu. Reed-mats that are made from bulrush are called Seua Gajude, mats woven from rattan are called Seua Wai, mats made from bamboo are named Seua Lampaen and pandanas reed-mats are given the name Seua Toei. Most woven reed-mats will be made within the family during free time away from farming. Currently, there are weaving groups whose members help one another in reed-mat creation using additional support from governmental initiatives. The government sponsorship is used as developmental assistance with group needs, namely capital, purchasing seeds, marketing and production.

In the past, reed-mat weaving in Maha Sarakham Province had the objectives of creating products for use in the family, replacing older mats and in the custom of donating to the community temple. Products had design characteristics only as sheets for sitting or sleeping on. Technological advancements, in tandem with higher levels of community organization, led to training in the transformation of reed-mats from their original form as 
flatsedge reed-mats. The combination of community development and a larger base of knowledgeable people caused the objectives of reed-mat weaving to shift from use in the family to production for sale. The design characteristics also changed from sheet-style mats to newer forms in order to meet consumer requirements and demand for benefit and usability, which generated increased income in the community. However, current income from the production of reed-mats has decreased owing to the increase of production costs, including raw materials, fertilizers, pesticides, labour and machinery. The number of consumers is also decreasing and valuable knowledge is being lost concerning administration, production, management and marketing. Additionally, the variety of products, shape, design, colour, form and style are not standardised and do not meet market needs.

For these reasons, the researcher was interested in studying the application of indigenous folk wisdom concerning the management of commercial reed-mat production in Maha Sarakham Province, Thailand. The research was designed to use the body of knowledge to develop and improve production design, while also generating income for the community by remembering and retaining ancestral folk wisdom. This will mean a permanent fixed income for the community, as well as the continuation of community folk wisdom.

\section{Research Objectives}

The research objectives for this study were threefold: (a) to study the history of the application of local wisdom in the management of commercial reed-mat production in Maha Sarakham Province, Thailand; (b) to study the present condition of and problems with the application of local wisdom in the management of commercial reed-mat production in Maha Sarakham Province, Thailand; (3) to study patterns in the application of local wisdom in the management of commercial reed-mat production in Maha Sarakham Province, Thailand.

\section{Research Methodology and Scope}

This study, the application of indigenous folk wisdom concerning the management of commercial reed-mat production in Maha Sarakham Province, Thailand, used a qualitative research method. The contents of this research include the history of reed-mat production, current conditions of and problems with the application of local wisdom in the management of commercial reed mat production and the patterns of application of local wisdom in the management of commercial reed mat production in Maha Sarakham Province, Thailand. Data was collected from document study, field study and detailed participatory research. Field study data was collected by survey, interview, observation, focus-group discussion and workshop. The data was then analyzed, including participatory action research (PAR), in order to achieve concrete factual data. This research began in October 2011 and finished in September 2012.

The research area comprised reed-mat weaving groups in Baan Phaeng, Kosum Phisai District, Maha Sarakham Province, Thailand, which were selected using a purposive sampling method. This research area was selected as it is a center of reed-mat handicraft production and products are sent to a wide area. There are governmental institutions that are interested in and order reed-mat products in different forms for use in public service and, as products are able to be sold easily, this aids the development of indigenous folk wisdom application in reed-mat production.

The population of the study included staff concerned with support of reed-mat weaving in both governmental and private sectors, members of the community and other individuals involved in the application of folk wisdom for the management of commercial reed-mat production in Maha Sarakham Province, Thailand. The research sample was classified into three groups.

The first group of key informants was comprised of individuals able to provide in-depth data regarding the application of folk wisdom in reed-mat production. A total of twenty individuals included government officers in institutions providing support to reed-mat production. Five individuals were from community development groups and organizations responsible for the area. Five individuals were from the private sector, including officers in institutions providing financial support, officers of community activities in reed-mat weaving and merchants involved in management of production for market sale. The remaining ten individuals consisted of committee members and local experts with knowledge of reed-mat production management in the community. The second group of thirty casual informants was comprised of members from weaving groups in Baan Phaeng, Kosum Phisai District, Maha Sarakham Province. The final group of general informants contained general staff involved with the management of reed-mat production and totaled forty individuals.

Domestic and international research documents were studied concerning folk wisdom in reed-mat production, development of products, law, regulations, concepts and theories in social science, anthropology and culture. Field study was conducted in the research area using the research tools of basic survey, informal and formal interview, in-depth interview, participant and non-participant observation, focused group discussion and 
workshop. Throughout the research a participatory action research method (PAR) was employed in the research area in order to achieve concrete factual data.

The pre-research phase was started by creation of a build-up report and survey and study of prospective communities for research. Selection of a community for the research was undertaken, focusing on communities with reed-mat production networks in Maha Sarakham Province, Thailand. The researcher then entered the community and informed the locals of the research proposal, establishing a cooperative network. The research phase began with problem identification and diagnosis, followed by project appraisal and identification. The final three stages of the research phase were planning, implementation and monitoring and evaluation.

During the investigation, the researcher applied a number of research techniques. A structured interview technique was used in accordance with the concept of the research. An un-structured interview technique was used with a group of knowledgeable experts before searching for individuals and asking about the history of application of folk wisdom in the management of commercial reed-mat production. Observation was employed in two forms: participant observation and non-participant observation. Non-participant observation was used throughout the community to study lifestyle and general community data regarding the management of commercial reed-mat production. Participant observation was used in accordance with the objectives of the research. Focused group discussion was used to gather opinion of study group members regarding the current conditions of and problems with application of folk wisdom in the management of commercial reed-mat production. A workshop was used to gather opinion of all informants in order to create a model for application of folk wisdom in the management of commercial reed-mat production.

Data classification of document study was conducted in line with the research objectives. Field research data from all collection methods was noted or recorded, paraphrased, separated into categories and important elements or issues were identified. Research anomalies and contentious data were isolated in preparation for reentry into the field for verification. All research and field data that was collected over the course of the study was verified using an investigator triangulation method. For data requiring further validation in the field, a methodological triangulation technique was used in the verification process.

Analytic induction and typological analysis were then used to examine the data. Analytic induction is a method of interpretation from concrete data, visible phenomena witnessed by the researcher or numerous events. Data is used to formulate theories. If the theories are not confirmed by the research, this constitutes a working hypothesis. If the theories are confirmed by the research, conclusions can be drawn, such as composition of popular practice, analysis of the researcher, selection and constraints of research time and their meaning for the work of organizations, lifestyle and reed-mat production. Typological analysis is the separation of data into typologies based on continuous events according to culture, wisdom, concepts and theories. It is a method of data analysis that will analyze the research system. The typologies used in this research were acts (continuous events, situations or behavior), activities (events, situations or customs related to people and groups), meaning (explanation and communication of the meaning of actions), relationship (interaction and connections between people), participation (individual engagement in activities and personal adaptation) and settings (situations or conditions of activities).

The researcher studied data from books, documents and related research from interviews, surveys and focus group discussions. This data was analyzed according to the research objectives and the defined research concept by using theories and research within the scope of the study. The method used for data analysis and explanation of results was descriptive analysis.

\section{Research Results}

The history of the application of local wisdom in the management of commercial reed mat production in Maha Sarakham Province, Thailand is divided into two periods. The first period dated from 1978 to 2003 and the second period dates from 2004 to the present day.

Materials used in past reed-mat production were flatsedge or jute. The mats were woven in weaving mills or on rectangular hard-wood weaving frames about two metres in width and two and a half metres in length. These frames were used for weaving nylon. There were reed battens made from padouk timber, or other hardwoods. These reed battens were bored with holes to allow the nylon to be threaded through during the weaving process. The battens could be long or short, depending on the size of the mat. There was a guide rod to thrust the thread of flatsedge. The rod was made from two-metre-length bamboo that had been cut into a cylindrical shape. It was tapered at one end and slightly grooved at the other so that the thread could be fixed before being thrust into the loom. Initially the weaver would sit behind the loom to weave the strands of flatsedge or jute together. However, as the mat became larger, the weaver would be unable to reach further up the loom. As a result, two additional 
pieces of wood were required; the first was to be placed under the mat to ensure that the fabric remained taught, while the second was to be placed upon the loom and act as a seat for the weaver during the latter part of the process. There was also a metal rod inserted at the foot of the loom. The nylon was wrapped around the rod and tightened to stay taut. Thus, the eight characteristics of reed-mat production in Maha Sarakham Province from 1978 to 2003 were: (a) flatsedge; (b) jute; (c) mill and frame; (d) reed battens; (e) guide rods; (f) wooden bridge piece; (g) wooden top seat and (h) metal base rod.

In the past, the vertical threads were made from jute, Manila hemp or banana tree. However, the most popular material nowadays is straw or nylon as they are the easiest materials to source, sold everywhere, easy to use and convenient to use quickly. By contrast, jute, Manila hemp and banana tree disintegrate easily and are more time-consuming to turn into thread. For these reasons, jute, Manila hemp and banana tree have disappeared from the reed-mat weaving process.

The horizontal threads for reed-mat weaving were previously made from flatsedge and hand-woven. Nowadays there are industrial weaving factories that use commercial machinery. Both horizontal and vertical threads are made from multicolored plastic strands. The mats that are produced are plastic copies of handmade originals. They are woven on a long production line, just like factory fabrics and are distributed all over Thailand. Maha Sarakham Province is home to both factory-made mats and the hand-woven variety.

The weaving equipment used in the production process is classified into three groups. Firstly, equipment used to prepare raw materials consists of a knife or scythe to cut the flatsedge, a knife to split the flatsedge and lines to hang the flatsedge for drying and dyeing. Secondly, equipment used to weave and decorate the mats includes a wooden frame to weave the mat, a guide rod, a reed batten, a wooden top seat, scissors or a knife, a basket for materials, a rock or bottle to smooth and polish the mat and a clothes line. Thirdly, equipment used to form the mat into different products is comprised of a sewing machine, tools for cutting and sewing, scissors, a knife, a needle, cotton, a pencil, a ruler, an apron, paper, leather, plastic, a sponge and decorative materials.

There are five steps in current reed-mat production: (a) preparation of raw materials, specifically flatsedge threads from the surrounding natural environment; (b) weaving procedure - stringing of the vertical threads; (c) creation of the mat - battening the horizontal threads to form the mat; (d) finishing the edges - neatly cutting the ends of the flatsedge threads around the border of the mat; (e) decorating, shining and polishing - adding detail to the finished product.

Current styles of reed-mat products are divided into two classifications of use, rolled mats and folded mats. Current reed-mat designs have been created to enhance the beauty of reed-mats. These designs are adapted and influenced by silk weaving, whilst remaining true to the purpose of the mats. There are eleven design styles, which are composed of letter design, flower design, butterfly design, Shan design, Naga design, looped design, tie-dyed design, diamond-spray design, Khid design, turtle-scale design and golden shower tree flower design. The colours used to dye flatsedge threads are usually chemical dyes or scientific dyes, including yellow, green, red, dark blue, brown and black, as they are easy to find, convenient and fast to use.

For the study of current conditions of and problems with the application of local wisdom in commercial reed-mat production, the researcher used an interview technique and small discussion groups with manufacturers. These methods permitted the researcher to discover the working problems with reed-mat production.

The problem with management of raw materials and resources was the old and deteriorated condition of the tools and equipment required by the group, particularly the looms and reed battens. The consequence of this was that the production quality did not meet market and consumer requirements. The management of the production of reed-mats was also at an insufficient level. The product quality was not standardized, the raw materials were difficult to find, there were inflating production costs and stagnant returns. The group was also missing organization of activities and further education for continuous development of member handicraft skill and expertise. This included training, study tours and use of modern production technology. The overall result was the inability of group products to compete in the market.

Problems with the management of product development were the absence of designs and the absence of new product development. This was because there were no members of the group skilled in design and, as a result, future sales of the group will be negatively affected. There were also problems with inheritance, extension of results, conservation and restoration of reed-mat production wisdom. The majority of the population was ignorant to commercial reed-mat production and did not therefore place any importance upon the craft or its inheritance.

The problem with marketing management was that the group did not have transport for delivery and distribution 
of goods. Study of product transformation and distribution found that members of the group perform their own duties and lack the necessary cooperation and teamwork to change tasks. There is also no experience network. Production costs are high because production is time consuming and there is reliance upon a number of other production lines outside the community.

Problems with marketing administration were the lack of variety of community products, inconsistent product quality and lack of widespread product advertising in the market, which will negatively affect member income. Income and profits are low. Even though product transformation generates larger takings, it requires higher startup investment capital. The yield increase is cancelled out and results in a low profit margin. The weaving groups have low startup investment capital, which means that they are unable to expand and develop activities to enlarge their businesses. There is no standard system of accounting, auditing or balancing closed budgets, which means there is no way of knowing everyday profits and expenditure.

Research into production materials and equipment for application of local wisdom in the development of folding mats found that locals previously used rectangular frame floor looms. However, current weavers use raised looms and sit on a chair during production. This means that the weaver will not develop back pains and will be able to weave alone. It was found that locals use pre-woven reed-mat and cut it into three sections. The first section forms the left border of the mat, the second section forms the middle of the mat and the third section forms the right border of the mat. When the three sections have been gathered, they are fitted together and their edges trimmed and decorated to form a three-section folding mat. The finished product is called a folding mat and is fitted with a convenient carry-handle.

Research into product design and colour found that locals in the past had not developed reed mat designs. The majority would use basic designs and natural flatsedge colouring or natural dyes. Nowadays, application of local wisdom has led to design development and beautiful colours through the use of chemical or scientific dyes. People who see the mats want to buy and use them immediately to receive guests. People who sit on the mats are impressed by the development of design variety.

Research into costs found that locals in the past did not sell their goods, rather using them within the family, as souvenirs, as gifts to the temple or to barter with. The costs were cheap as most materials were home-produced or available in the surrounding community area. However, current application of local wisdom has caused the form of reed mats to change from rolled design to folded design, with either three or four folds. The transformation from flat, rolled mats to the folded variety is an advancement but involves higher costs because the materials and equipment used in the process are greater. These include flatsedge reeds, reed-mat sheets, other fabrics, needles, cotton, a sewing machine, cutting equipment such as scissors and knives, and drawing equipment such as tape measures, pencils, pens and rulers. The price of the mats varies according to length, width and beauty.

\section{Conclusion}

Occupations concerned with reed-mat handicraft weaving are suitable for lifestyle in the community, given the abundance of raw materials in the local area. Use of local wisdom for community benefit, increase of local cooperation and creation of income in the community will prevent the need for economic migration. If this is achieved, the community will be strengthened so that individuals can take care of themselves. However, concerning the calculation of production costing and reward, the handicraft should be supported or advanced to be able to sell at higher prices. Multiple product forms should be designed for a variety of uses, as the production costs are high. These products would strengthen the market and provide a more certain consumer base. In turn, opportunities for distribution of goods should be increased by organization of provincial product fairs across the country. This must be supplemented by contact and connection with government agencies for production assistance in order to eliminate middle-men in export and increase product integrity. The community weaving groups should assign members to find suitable markets in order to increase definite opportunities and distribution. Production should also show more concrete standards of costing and quality in order to generate positive basic attitudes among consumers regarding their trust of the product integrity. This is a way to improve the reputation and image of the organizations and clearly define the rewards and benefits of the products. The government sector must provide support and knowledge in the cultivation of plants used as raw materials in production, such as preventing and solving disease and pest problems, increase of yield and improvement of material quality. As the cost of using scientific colouring in the dyeing process is high, a way to reduce the production cost and conform to popular consumer colour preferences would be to use natural dyes that can be found in the surrounding environment, such as from mango bark, morinda citrifolia root, mangrove bark, jackfruit bark and jambolan plum. This should be studied and tested for suitability in further research 


\section{References}

Anon. (2000). Committee of Research, Education and Religion and Culture of the Ministry of Education. Bangkok: s.n.

Buakemtong, K. (2004). Community Potential Development Program (SML). Business Research Letters, 8(52), 10.

Committee of Industry Product Standards. (2003). Manufactured Community Products: Flatsedge Products (4th ed.). Bangkok: Ministry of Education.

Department of Technology. (1999). Local Wisdom. Bangkok: Rungsin Publishers.

Jaroenwongsak, K. (1998). Paradigm of Original Thai Culture and a Backwards Economy. Bangkok: Success Media.

Kaewtep, K. (1995). Development of Community Modernization. Bangkok: Catholic Council for Thailand Development.

Kanmag, K., \& Madjarat, T. (2006). Technique for turning Initial Theoretical Research into Practice. Bangkok: Tarnaksorn.

Ministry of the Interior. (1998). Independent Community Economy: Concept and Strategy. Bangkok: Suantongtin.

Nantanawanit, K. (2003). Anthropological study of the Lao community: A case study of Hat-Song-Khwae Village, Hat-Song-Khwae Sub-District, Tron District, Uttaradit Province. Master Dissertation, Mahidol University, Thailand.

National Committee of Education, Office of the Prime Minister. (1998). Way to strengthen Thai wisdom regarding educational management of local wisdom with required curriculum. Bangkok: s.n.

Pitakwong, J. (2000). Social and Cultural Change. Chiang Mai: Chiang Mai University.

Sadsangwon, N. (2000). Foundations of Anthropological Culture. Bangkok: Rama Publishing.

Tarmawat, J. (1995). Analysis of Isan Wisdom. Maha Sarakham: Mahasarakham University.

Tarmawat, J. (2000). Isan Wisdom (3rd ed.). Ubon Ratchatani: Siritam Offset.

Technology Promotion Association. (1992). Technology for Flatsedge Production. s.l.: s.n. 